\title{
Occurrence of Dens in Dente in Permanent Maxillary Lateral Incisors: A Case Report with Literature Review
}

${ }^{1}$ Nagaveni NB, ${ }^{2}$ Poornima P, ${ }^{3}$ Meghana SB

\begin{abstract}
Aim: The aim of this case report is to give a detailed review about the etiology, prevalence, clinical features, radiographic features and treatment of dens in dente along with the presentation of a case report.
\end{abstract}

Background: Dental anomaly is a complex interaction between genetic and environmental factors during the process of dental development. One such commonly seen anomaly is dens in dente which represents as an exaggeration or accentuation of a lingual pit. It is a developmental malformation where the etiology is the alteration in the normal growth pattern of the dental papilla during tooth development, resulting in invagination of the surface of the crown or root before calcification.

Case description: A 10-year-old female patient presented to the department, for the routine dental check-up. There was a coincidental diagnosis of a dental anomaly following which a preventive protocol was followed to rescue the teeth from further damage.

Conclusion: Early diagnosis and preventive intervention are important to save the teeth from the further carious lesion.

Clinical significance: As a pediatric dentist, the knowledge about the malformations and making the right decision for management is important.

Keywords: Bilateral permanent lateral incisors, Dens in dente, Preventive protocol.

How to cite this article: Nagaveni NB, Poornima P, Meghana SB. Occurrence of Dens in Dente in Permanent Maxillary Lateral Incisors: A Case Report with Literature Review. CODS J Dent 2017;9(2):50-54

\section{Source of support: $\mathrm{Ni}$}

Conflict of interest: None

\section{INTRODUCTION}

An anomaly is defined as something that is noticeably different or that deviates from the ordinary or normal. ${ }^{1}$ Dental anomalies are deviations of dental tissue origin and therefore are derived from the dental tissues, enamel,

\footnotetext{
${ }^{1}$ Professor, ${ }^{2}$ Professor and Head, ${ }^{3}$ Postgraduate Student

${ }^{1-3}$ Department of Pedodontics and Preventive Dentistry, College of Dental Sciences, Davangere, Karnataka, India

Cooresponding Author: Nagaveni NB, Professor, Department of Pedodontics and Preventive Dentistry, College of Dental Sciences, Davangere, Karnataka, India, Phone: +918971695506, email: nagavenianurag@gmail.com
}

dentin, or cementum. Anomalies can be extreme variations or just slight deviations. Dental anomalies are the defects caused by genetic disturbances or environmental factors during the development of tooth. ${ }^{2}$ Dens invaginatus is one such uncommon dental developmental anomaly seen in the permanent teeth. It is seen as a deep surface invagination of the crown or root, which is lined by enamel and resulting from the invagination of the enamel organ into the dental papilla during odontogenesis. ${ }^{3}$ Several authors have given a different name for this anomaly, such as Busch 1897 who suggested the name 'dens in dente' which implies the radiographic appearance of a tooth within a tooth. Hunter in 1951 suggested the term 'dilated composite odontome' which infers an abnormal dilatation of the dental papilla, Whilst Colby in 1956 recommended the use of 'gestant anomaly'. ${ }^{4}$ It is defined as a developmental anomaly characterized by a deep enamel-lined pit that extends for varying depths into the underlying dentine, often displacing the pulp chamber and sometimes altering the shape of the root. ${ }^{3}$ Some authors consider dens invaginatus as a deep folding of the foramen coecum during tooth development, resulting in a second apical foramen. ${ }^{5}$ The etiology of this condition has been presumed to be related to focal growth retardation, focal growth stimulation or localized external pressure on certain areas of the tooth bud. ${ }^{6}$ However, this fails to give an explanation regarding cases of bilateral dens invaginatus. The most common site of dens invaginatus is the maxillary lateral incisors. The identification of this anamoly is little difficult and needs a keen observation. In this article etiology, prevalence, classification, clinical and radiographic features, and treatment options for dens invaginatus is described in detail along with a case presentation. Choice of treatment varies from preventive aspects in lenient cases to extraction in severe cases.

\section{CASE DESCRIPTION}

A 10-year-old female patient reported to the Department of Pedodontics and Preventive Dentistry, College of Dental Sciences, Davangere, Karnataka for the routine dental check-up and follow-up. The patient was healthy with no significant medical history. History of the patient revealed that she had past dental experiences 
and is undergoing required treatment for the fractured tooth. The extraoral examination did not indicate any significant finding. On detailed intraoral examination, there was Ellis class III fracture in relation to 11 (permanent maxillary right central incisor) which was under endodontic treatment, initial proximal carious lesion in relation to 54 (primary maxillary right first molar), coincidental diagnosis of the dental malformation in relation to 12,22 (permanent maxillary lateral incisors bilaterally) (Fig. 1). It was not associated with any swelling or sinus tract. Radiographic evaluation was advised to the patient to know the details of the dental malformation. The radiographic evaluation revealed the malformations to be dens invaginatus also popularly called dens in dente in both the permanent lateral incisors (Figs 2 and 3). The maxillary right lateral incisor being the prominent one (Fig. 1). The periapical region had a normal radiographic appearance with no significant changes. The tooth also responded well, showing vital signs on electric and thermal pulp testing. However, clinically both

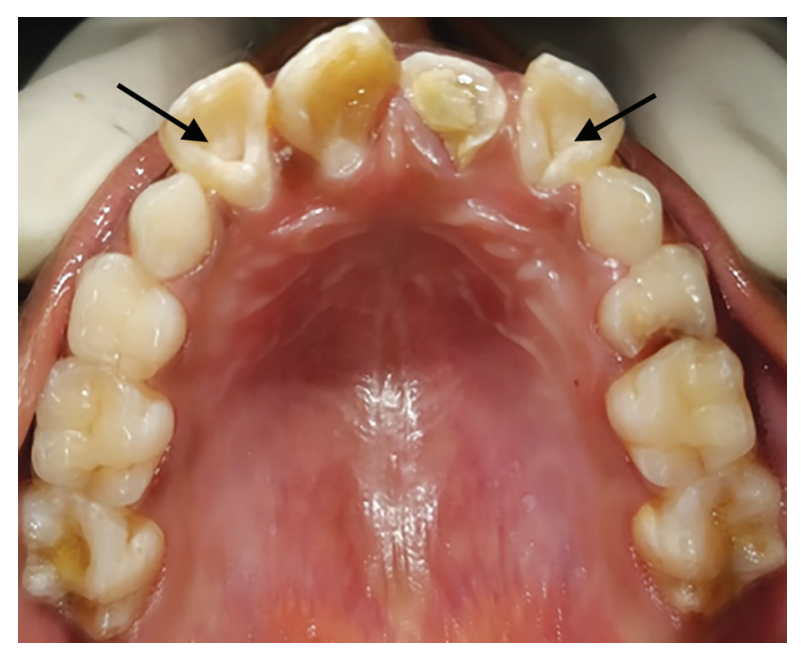

Fig. 1: Permanent maxillary lateral incisors with deep pits (arrows)

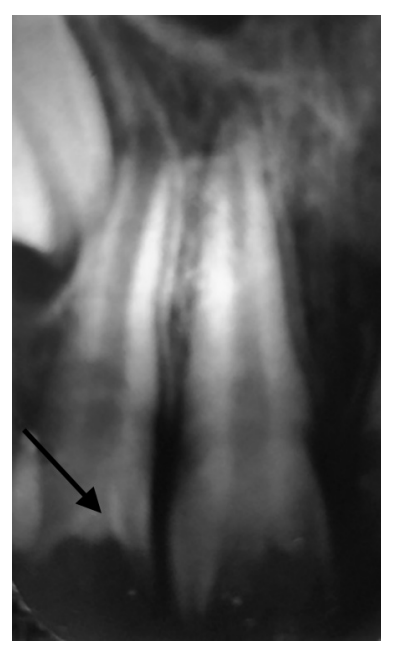

Fig. 3: Radiograph showing dens invaginatus in 22 (left lateral incisor) (arrows) the lateral incisors had deep pits and fissures and plaque accumulation, which predisposes dens invaginatus to caries, cavitation and further to pulpitis. So, a preventive protocol was followed to prevent and protect the tooth from caries. Thorough oral prophylaxis of both the arches was done to remove debris, plaque, and calculus. Pits were sealed with a sealant (3M ESPE clinpro pit and fissure sealant) (Fig. 4). Teeth were checked and made sure had no occlusal interference. Regular recall visits were contemplated to the patient.

\section{DISCUSSION}

In this case report, dens invaginatus was seen in the permanent maxillarylateral incisors which were accidentally diagnosed during the intraoral examination.

\section{Etiology}

The exact etiology of dens invaginatus still remains controversial. The etiology of dens invaginatus has been explained

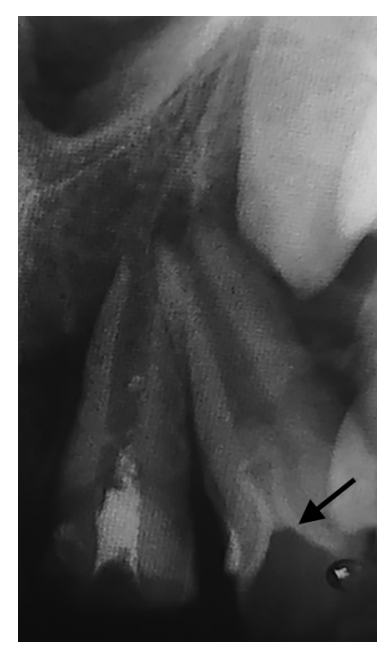

Fig. 2: Radiograph showing dens invaginatus in 12 (right lateral incisor) (arrows)

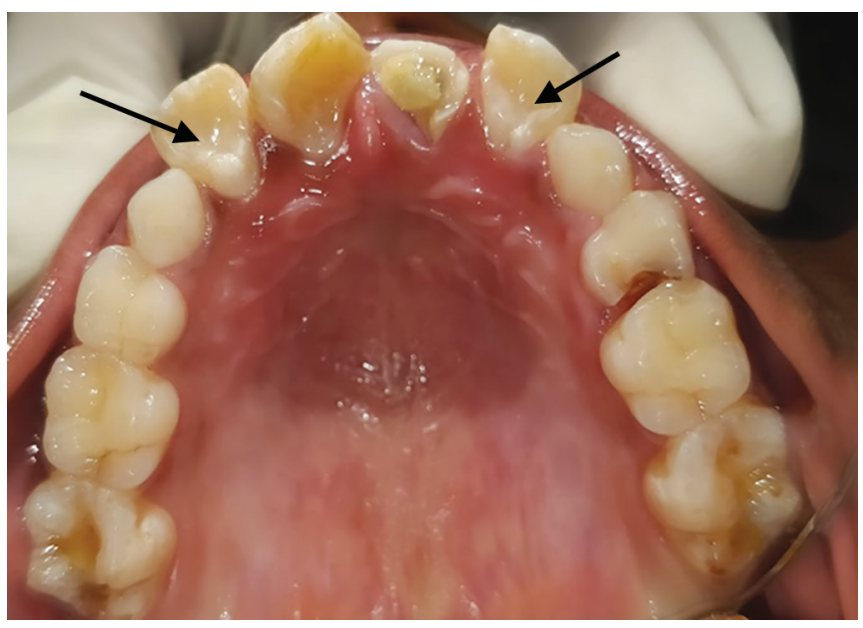

Fig. 4: Pits sealed wrt 12, 22 using a pit and fissure sealant (arrows) 
by a number of theories. It has been put forward by Atkinson et al., that the growing pressure of dental arch results in buckling of enamel organ. ${ }^{7}$ Rushton et al., suggested that the invagination is a result of a rapid and aggressive proliferation of a part of internal enamel epithelium invading the dental papilla. ${ }^{8}$ Oehlers et al., proposed that distortion of the enamel organ during tooth development and subsequent protrusion of a part of the enamel organ will lead to the formation of an enamel-lined channel ending at the cingulum or occasionally at the incisal tip. ${ }^{9}$ Kronfeld et al., suggested that it results from a focal failure of growth of internal enamel epithelium. ${ }^{10}$ The "twin-theory" suggested that dens invaginatus is the result of the fusion of two tooth germ. ${ }^{11}$ Infection was also considered to be responsible for the malformation of the tooth. ${ }^{12}$ Gustafson and Sundberg et al. stated trauma as a causative factor for dens invaginatus. ${ }^{13}$ The genetic factor was also taught to play a role in the etiology of dens in dente. ${ }^{3}$ Shulze et al. stated that it may result from a deep infolding of foramen caecum during tooth development which in some cases may result in a second apical foramen. ${ }^{5}$ Ketunen et al., in his article, mentioned about the ectomesenchymal signal system between dental papilla and the internal enamel epithelium that affects tooth morphogenesis. These signals have specific roles such as tooth morphogenesis and the folding of enamel organ which might lead to the formation of dens invaginatus. ${ }^{14}$

\section{Prevalence}

The prevalence of dens invaginatus ranges from 0.04 to $10 \% .{ }^{15}$ It is a common dental anomaly encountered in the permanent lateral incisors, central incisors, premolars, canines, and molars. Involvement of dens invaginatus in primary teeth has been reported uncommon. A strong maxillary predominance is seen with no gender difference. Studies have shown, type I as commonly involved with prevalence of $81.25 \% .{ }^{16}$ Table 1 shows the case report of dens in dente in permanent maxillary lateral incisors.

\section{Classification}

The most popularly known classification is Oehler's classification, given in 1957. He described them as coronal invaginations and radicular invaginations and classified them as: ${ }^{9}$

- Type I: An enamel-lined minor from occurring within the confines of the crown not extending beyond the cementoenamel junction.

Table 1: Reported cases of dens in dente in permanent maxillary lateral incisors

\begin{tabular}{|c|c|c|c|}
\hline $\begin{array}{l}\text { SI. } \\
\text { no }\end{array}$ & Author and year & No of teeth involved and type of dens in dente & Treatment done \\
\hline 1. & Frank et al. ${ }^{17} 1965$ & Upper left lateral incisor, type I & Root canal therapy \\
\hline 2. & William et al. ${ }^{18} 1975$ & Upper right lateral, upper left lateral incisor, type I & Pit and fissure sealants \\
\hline 3. & Eric et al. ${ }^{15} 1977$ & Upper right lateral incisor, type I & Root canal therapy \\
\hline 4. & Feruguson et al. ${ }^{19} 1980$ & Upper right lateral incisors, type III & Apexification \\
\hline 5. & Carlos et al. ${ }^{20} 1999$ & Upper left lateral incisor,type I & Root canal therapy \\
\hline 6. & William et al. ${ }^{21} 2002$ & Upper right lateral incisor, type II & Microscopic removal of dens invaginatus \\
\hline 7. & Nalapatti et al. ${ }^{22} 2004$ & Upper right lateral incisor, type I & Devitalization \\
\hline 8. & Steffen et al. ${ }^{23} 2005$ & Upper left lateral incisor, type II & Root canal therapy \\
\hline 9. & Subay et al. ${ }^{24} 2005$ & Upper right lateral incisor, type I & Conventional root canal therapy \\
\hline 10. & Jimenez et al. ${ }^{25} 2006$ & Upper left lateral incisor, type I & Pit and fissure sealant \\
\hline 11. & Sauveur et al. ${ }^{26} 2007$ & Upper left lateral incisor, type I & Conventional root canal therapy \\
\hline 12. & Zengin et al. ${ }^{27} 2009$ & Upper right lateral incisor, type I & Preventive restoration in palatal surface \\
\hline 13. & Keles et al. ${ }^{28} 2008$ & Upper right lateral incisor, Type I & Root canal therapy \\
\hline 14. & Kotoor et al. ${ }^{29} 2011$ & Upper right lateral incisor, Type I & Root canal therapy \\
\hline 15. & Jie et al. ${ }^{30} 2013$ & Upper left lateral incisor, type II & Revascularization \\
\hline 16. & Ali et al. ${ }^{31} 2015$ & Upper left lateral incisor, type II & Two visit root canal therapy \\
\hline 17. & Asma et al. ${ }^{32} 2015$ & Upper right lateral incisor, type II & Root canal therapy \\
\hline 18. & Azar et al. ${ }^{33} 2015$ & Upper right lateral incisor, type III & Root canal therapy \\
\hline 19. & Nagaveni et al. ${ }^{34} 2015$ & Upper right and left incisors, type II & Pit and fissure sealants \\
\hline 20. & Prerna et al. ${ }^{35} 2017$ & Upper right lateral incisor, type I & Nonsurgical endodontic treatment. \\
\hline 21. & Negar et al. ${ }^{36} 2017$ & Upper right lateral incisor, type I and type III & MTA in apical plug \\
\hline 22. & Shaik et al. ${ }^{37} 2018$ & Upper right lateral incisor, type I & Root canal therapy \\
\hline 23. & Mohsen et al. ${ }^{38} 2018$ & Upper right lateral incisor, type II & Conventional root canal therapy \\
\hline
\end{tabular}


- Type II: An enamel-lined form which invades the root but remains confined as a blind sac. It may or may not communicate with the dental pulp.

- Type IIIA: A form which penetrates through the root and communicates laterally with the periodontal ligament space through a pseudo-foramen. There is usually no communication with the pulp, which lies compressed within the root.

- Type IIIB: A form which penetrates through the root and perforating at the apical area through a pseudoforamen. The invagination may be completely lined by enamel, but frequently cementum will be found lining the invagination.

Radicular invaginations are rare and are thought to arise secondary to a proliferation of Hertwig's root sheath with the formation of a strip of enamel that extends along the surface of the root. ${ }^{1,39}$ Based on the above classification, the present cases were classified as type II dens invaginatus.

\section{Clinical Features}

In a few cases, the enamel-lining is incomplete, and communications may exist between the invagination and the pulp. ${ }^{40}$ The invagination allows entry of irritants into an area which is separated from pulpal tissue by only a thin layer of enamel and dentine and presents a predisposition for the development of dental caries.

Therefore, pulp necrosis often occurs rather early, within a few years of eruption, sometimes even before root end closure. While other cases have reported sequelae of undiagnosed and untreated coronal invaginations which includes abscess formation, retention of neighboring teeth, and displacement of teeth, cysts, internal resorption, and facial cellulitis. ${ }^{41}$ General features of teeth with dens invaginatus include peg-shaped formation, incisal notching, increased labiolingual and mesiodistal diameter, conical morphology and the presence of an enlarged palatal cingulum or cusp. ${ }^{42}$

\section{Radiographic Features}

The radiographic features of types I and II dens invaginatus are similar. The anomaly may vary in size and shape from a loop like pear-shaped or slightly radiolucent structure to a severe form resembling tooth within a tooth. The outline of the defect is generally well defined with an opaque layer of enamel.

Type III type of dens invaginatus is more difficult to identify and fully locate, as it is superimposed on the root canal system exiting apically from within the root canal. This apical formation can present with an immature apex and most cases present with a well- established periapical lesion. ${ }^{4}$ The radiograph of the present case shows dens in dente in both right and left permanent maxillary lateral incisors. There is loop like radiolucent area in the crown part of 12, 22 (right and left permanent maxillary lateral incisors) which resembles tooth within a tooth confirming the anomaly as dens in dente. The outline of the loop is well defined in the right maxillary lateral incisor and not very prominent in left lateral incisor. The periapical region shows an open apex with no significant changes.

\section{Treatment Choices for Dens Invaginatus}

Choice of treatment varies from preventive aspects in lenient cases to extraction in severe cases. In this case report, sealing of the pits as a preventive protocol has been applied. Similar cases which have been reported with the different treatment modalities of dens invaginatus are:

- Sealing of deep pits in dens invaginatus. ${ }^{41}$

- Root canal treatment. ${ }^{42}$

- Endodontic apical surgery. ${ }^{43}$

- Microscopic removal of dens invaginatus. ${ }^{44}$

- Extraction. ${ }^{44}$

\section{CONCLUSION}

As the etiology is still controversial and prevalence is not clear, clearly further scientific investigation is required regarding dens invaginatus. Also, as in this case report, early identification and preventive intervention rescued the teeth from further dental diseases, careful diagnostics and adequate treatment planning are required.

\section{REFERENCES}

1. Neville BW. Abnormalities of teeth. In: Neville B, Damm DD, Allen CM, Bouquot J Oral and Maxillofac Pathol. 2nd ed. Philadelphia: W.B. Saunders; 2002. pg. 80-82.

2. Hartsfield JK, Cameron AC. Acquired and Developmental Disturbances of the Teeth and Associated Oral Structures. InMcDonald and Avery's Dentistry for the Child and Adolescent. Tenth Edition. 2016; pp. 39-79.

3. Sapp JP, Eversole LR, Wysocki GP.Contemporary Oral and Maxillo-facial Pathology. 2nd ed. Mosby. 2003:8-9.

4. Hulsmann M. Dens invaginatus: aetiology, classification, prevalence, diagnosis and treatment considerations. Int Endod J 1997;30:79-90.

5. Hegde V, Morawala A, et al. Dens in Dente: A Minimally Invasive Nonsurgical Approach! J Conserv Dent 2016;19(5):487489.

6. Tsurumachi T, Hayashi M, et al. Non-surgical root canal treatment of dens invaginatus type 2 in a maxillary lateral incisor. Int Endod J 2002;35(1):68-72.

7. Atkinson SR. The permanent maxillary lateral incisor. Am J Orthodont 1943;29:685-698.

8. Rushton MA. A collection of dilated composite odontomes. Br Dent J 1937;63:65-85. 
9. Oehlers FAC. Dens invaginatus. Part I: variations of the invagination process and association with anterior crown forms. Oral Surg Oral Med Oral Pathol 1957;10:1204-1218.

10. Nagaveni NB, Umashanikara KV, et al. Permanent mandibular incisor with multiple anomalies-report of a rare clinical case. Braz Dent J 2011;22(4):346-350.

11. Brill WA, Phillips JE. Double dens invaginatus. Oral Surg Oral Med Oral Pathol Oral Radio 1974; 37(1):139-140.

12. Munir B, Tirmazi SM, et al. Dens invaginatus: aetiology, classification, prevalence, diagnosis and treatment considerations. Pak Oral Dent J 2011;31(1).

13. Gustafson G, Sundberg S. Dens in dente. Br Dent J 1950; 88:83-88,111-122,144-146.

14. Kettunen P, Laurikkala J, et al. Associations of FGF-3 and FGF-10 with signaling networks regulating tooth morphogenesis. Dev Dyn 2000; 219(3):322-332.

Hovland EJ, Block RM. Non recognition and subsequent endodontic treatment of dens invaginatus. J Endod 1977;3(9):360362.

15. Senia ES, Regezi JA. Dens evaginatus in the etiology of bilateral periapical pathologic involvement in caries-free premolars: case report. Oral Surg Oral Med Oral Pathol 1974;38(3):465-468.

16. Everett FG, Kramer GM. The disto-lingual groove in the maxillary lateral incisor; a periodontal hazard. J Periodontol 1972;43(6):352-361.

17. Conklin WW. Double bilateral dens invaginatus in the maxillary incisor region. Oral Surg Oral Med Oral Pathol 1975;39(6):949-952.

18. Ferguson FS, Friedman S, et al. Successful apexification technique in an immature tooth with dens in dente. Oral Surg Oral Med Oral Pathol Oral Radio 1980;49(4):356-359.

19. Bóveda C, Fajardo M, et al. Root canal treatment of an invaginated maxillary lateral incisor with a C-shaped canal. Quintessence Int 1999;30:707-711.

20. Girsch WJ, Mc Clammy TV. Microscopic removal of dens invaginatus. J Endod 2002;28:336-339.

21. Nallapati S. Clinical management of a maxillary lateral incisor with vital pulp and type 3 dens invaginatus: a case report. J Endod 2004;30(10):726-731.

22. Steffen H, Splieth C. Conventional treatment of dens invaginatus in maxillary lateral incisor with sinus tract: one year follow-up. J Endod 2005;31:130-133.

23. Sübay RK, Kayataş M. Dens invaginatus in an immature maxillary lateral incisor: a case report of complex endodontic treatment. Oral Surg Oral Med Oral Pathol Oral Radio Endod 2006;102(2):e37-e41.

24. Jiménez-Rubio A, Segura JJ, et al. Multiple dens invaginatus affecting maxillary lateral incisors and a supernumerary tooth. Dent Traumatol 1997;13(4):196-198.

25. Sauveur G, Roth F, et al. Surgical treatment of a periradicular lesion on an invaginated maxillary lateral incisor (dens in dente). Int Endod J 2007;30(2):145-149.
26. Zengin AZ, Sumer AP, et al. Double dens invaginatus: report of three cases. Eur J Dent 2009;3(1):67.

27. Keleş A, Çakıcı F. Endodontic treatment of a maxillary lateral incisor with vital pulp, periradicular lesion and type III dens invaginatus: a case report. Int Endod J 2010;43(7):608-614.

28. Kottoor J, Murugesan R, et al. A maxillary lateral incisor with four root canals. Int Endod J 2012 Apr;45(4):393-397.

29. Yang J, Zhao Y, et al. Pulp revascularization of immature dens invaginatus with periapical periodontitis. J Endod. 2013;39(2):288-292.

30. Izaz S, Bolla N, et al. Endodontic Management of Calcified Oehler's Type IIIb Dens Invaginatus in Permanent Maxillary Lateral Incisor Using Cone Beam Computed Tomography. J Dent 2015;19(3):243.

31. Zoya A, Ali S, et al. Double dens invaginatus with multiple canals in a maxillary central incisor: retreatment and managing complications. J Endod 2015;41(11):1927-1932.

32. Heydari A, Rahmani M. Treatment of dens invagination in a maxillary lateral incisor: A case report. Iran Endod J 2015;10(3):207.

33. Nagaveni NB, Pathak S, et al. An Overview of Dens Invaginatus with Report of 2 Cases. J Clin Exp Pathol 2015;5(238):21612681.

34. Tripathi P, Singh AR, et al. Nonsurgical endodontic management of maxillary lateral incisor with dens invaginatus and periradicular lesion. Int J Pedod Rehab 2017;2(2):81.

35. Norouzi N, Kazem M,et al. Nonsurgical management of an immature maxillary central incisor with type iii dens invaginatus using MTA plug: A Case Report. Iran Endod J 2017;12(4):521.

36. Izaz S, Bolla N, et al. Endodontic Management of Calcified Oehler's Type IIIb Dens Invaginatus in Permanent Maxillary Lateral Incisor Using Cone Beam Computed Tomography. J Dent 2018;19(3):243.

37. Afkar M, Gholamshahi M, et al. Nonsurgical Treatment of type ii dens invaginatus in a maxillary lateral incisor using cone-beam computed tomography. Iran Endod J 2018; 13(1):132.

38. Alani A, Bishop K. Dens invaginatus. Part 1: classification, prevalence, aetiology. Int Endod J 2008;41(12):1123-1136.

39. Hitchin AD, Mchugh WD. Three coronal invaginations in a dilated composite odontome. Brit Dent J 1954;97:90-92.

40. Green Field RS, Cambruzzi JV. Complexities of endodontic treatment of maxillary lateral incisors with anomalous root formation. Oral Surg Oral Med and Oral Pathol 1986;62:82-88. 66.

41. Fujiki Y, Tamaki N, et al. Clinical and radiographic observations of dens invaginatus. J Dento Maxillofacial Radio 19743:343-348.

43. Aguiar CM, Ferreira JP, et al. Type 2 dens invaginatus in a maxillary lateral incisor: a case report of a conventional endodontic treatment. J Clin Pediatric Dent 2008;33(2):103-106.

44. Ortiz P, Weisleder R, et al. Combined therapy in the treatment of dens invaginatus: case report. J Endod 2004;30:672-674. 